\title{
Contents Refined for Implentmenting Association Learning of Students with Modern Techniques
}

\author{
Menglong Wang, Wenyi Shao, Zhaorong Shi, Tianhao Zhu, Xiao Liu, Deng-Guang Yu* \\ School of Materials Science \& Engineering, University of Shanghai for Science \& Technology \\ Shanghai 200093, China \\ E-mail: ydg017@usst.edu.cn
}

\begin{abstract}
The period of junior high school is a good time to train the students to increase their understanding about learning methods and to study their school subjects in an associated manner. In this paper, an example about association learning is exhibited with a modern technique - electrospraying, which is regarded as a supporting base. A series of school subjects such as "science", "mathematics", "physics", "chemistry" and "practice" can be realized contents refined with electrospraying as teaching materials, which should be also useful for provoking the students' study interests and enriching their learning contents. Meanwhile, some advanced learning methods such as analogical learning and integrated learning (linking theory with practice) can be also shown to them. Modern techniques can be used as teaching materials for all levels of education, including the teaching on the students in junior high school. Certainly, they can be also utilized as school-based training materials to their teachers for personal individual developments.
\end{abstract}

Keywords-Association learning; Electrospraying; Junior high school; School subjects

\section{INTRODUCTION}

Modern techniques are the brightest civilization fruits of our human kind. To some extents, they act like another sun to shine our modern life. The achievement of one advanced technique needs the effort of many talents and through many years. The contents buried within one modern technique can be kicked out for teaching at all levels of education, or it can provide teaching materials for students in primary school, junior high school, senior high school, university, and also the professional institute (Fig. 1).

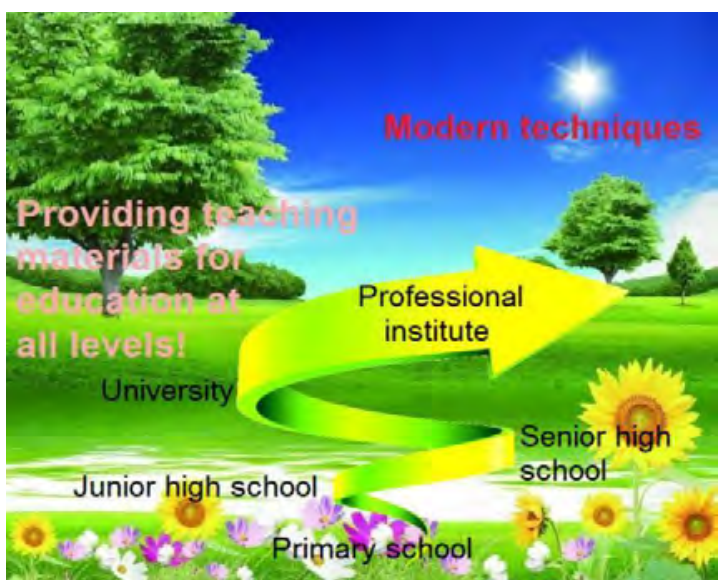

Fig. 1 The abundant teaching materials from modern techniques for education at all levels.
In China, the junior high schools open a series of subjects to their students. These subjects include the most fundamental ones (such as Mathematics, Sports, Chinese, and English) and also some other important subjects for cultivating the students' all-round capabilities (such as Science, Practice, Physics, Chemistry and Morality lessons). It maybe because that the teaching of these subjects are at the initial stages, they are given to the students in a totally separate manner. Few efforts have spent on the comprehensive lessons that the related contents are imparted to the students in an associated or combined manner. But for the students in the junior high schools (who have studied knowledge for six year of primary school and are growing fast in all the aspects), it should be better to show them the advanced and integrated study methods. These kinds of studies often need a clue to link them together. The modern techniques can just provide this type of soils for supporting the implementation of association learning (Fig. 2). Certainly, they can also provide opportunities for analogical learning and integrated learning for training both the students and also their teachers, who are striving to expand personal developments in the professional career.

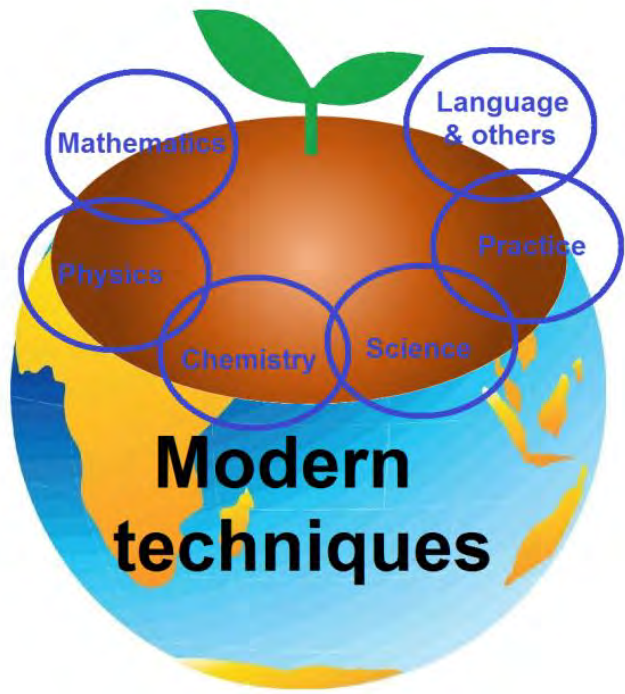

Fig. 2 With modern techniques as a strong support, a series of school subjects can be taught with contents refined from electrospraying as the teaching materials in an association manner.

Electrospraying is one of the most popular modern techniques due to the surge of nanoscience and 
nanotechnology [1-3]. It belongs to the electrohydrodynamic atomization methods, which electrostatic energy is exploited to create advanced nanomaterials [4-11]. During the past several decades, there are thousands of publications reporting the progresses of this advanced technique. A diagram of a coaxial electrospraying process is shown in Fig. 3. Different with numerous traditional methods for producing nanomaterials, electrospraying generates solid nanoparticles through electrical repelling forces. Often a syringe pump is exploited to drive the working fluid in a quantified way, a spray head is exploited to guide the fluid into the electrical field, a power supply is utilized to provide the high voltage, and a collector is utilized to collect the prepared nanoparticles. In this paper, we show that this technology can 1) provide many examples and teaching materials for provoking study interests of students in a junior high school about mathematics, physics, and chemistry, practices, and also language; 2) provide contents for association learning between science and other school subjects; and 3) provide teaching materials for analogical study and integrated learning.

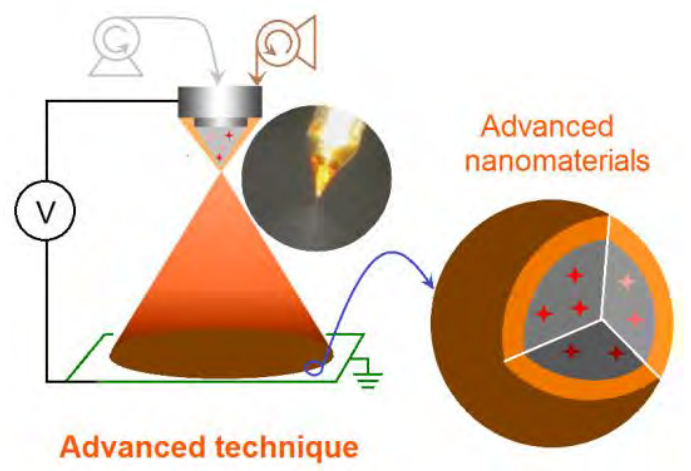

Fig. 3 An example of the modern advanced technique--modified coaxial electrosraying and the corresponding nanomaterials--core-shell nanoparticles.

\section{TEACHING MATERIALS FOR MATHEMATICS AND ASSOCIATION LEARNING}

In pharmaceutics, drug sustained release is one of the important goals for drug delivery through oral administration. The traditional oral dosage forms such as capsules and tablets (Fig. 4) often result several times administration one day and a fluctuation of drug concentrations in blood, which is not safe for the patients [12]. The best sustained release profile is the linear release, or zero-order release. The typical expression of linear release is the unary equation, i.e. $\mathrm{y}=\mathrm{ax}+\mathrm{b}$.

The unary equation is the study content arranged in the eighth grade in the junior high school in China. The direct explanation of this equation often make it difficult for the students to understand its true meaning. With the drug administration as an example, and the therapeutic effect can keep a constant state with time, it should be more convenient for them because almost all the students have the experiences. The electrosprayed nanoparticles and also electrospun nanofibers can provide this kind of drug release characteristics [13-16]. Thus, that association learning of mathematics, science and also the life experiences are combined together for better study effects is feasible.

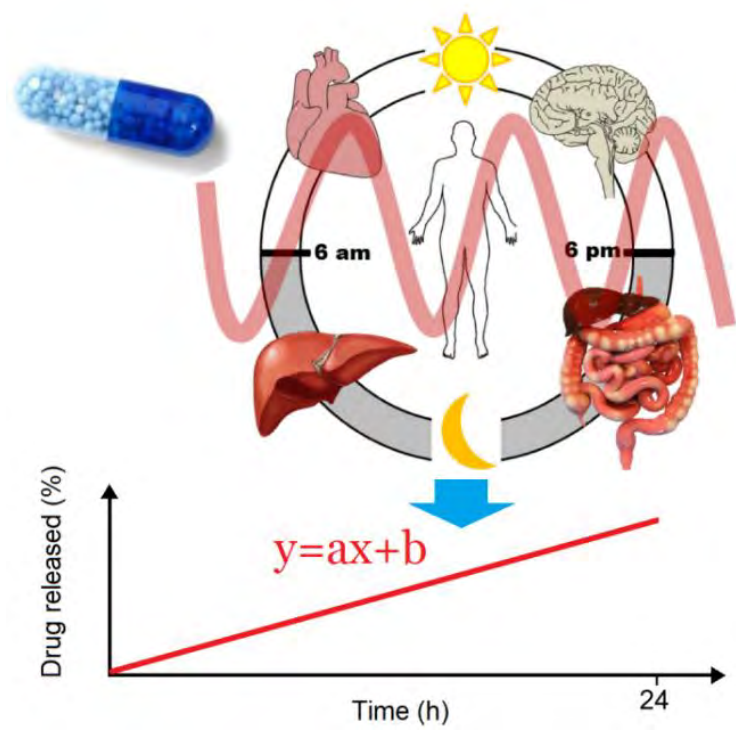

Fig. 4 Contents refined from core-shell nanoparticles for education in Junior Middle School about mathematics - One element first order equation [12].

\section{TEACHING PHYSICS FOR MATHEMATICS AND ASSOCIATION LEARNING}

In china, the students in the eighth grade in junior high school will open the new school subject for them - physics. In the beginning of their study, the lessons are about some most fundamental concepts such as force. There are a series of different kinds of forces in nature. The mechanical force, frequently sensed naturally by the students, is easy to be accepted after classes. However, some other types of forces, (such as electrical forces, magnetic field force, and biological force), should not be an easy thing for them to grasp.

In the electrospraying process, the forces can be "seen" through the Columbic exposion phenomenon [17], as shown in the diagram of Fig. 5. With a witness of the effect of electrostatic forces on the working fluid (in which there are many interesting phenomena [18-20]), the students should be more convinced about the electrical forces. Correspondingly, that association learning of physics, science and the scientific phenomenon are combined together for better study effects is possible. 


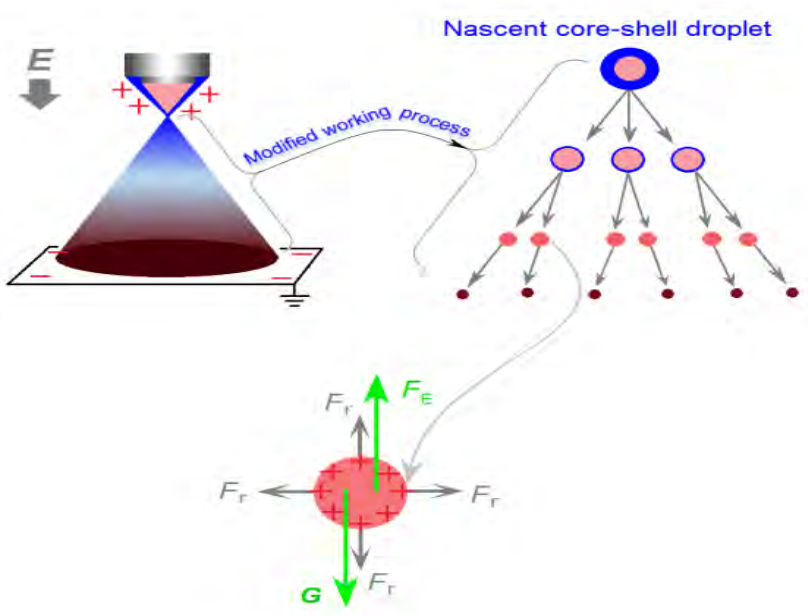

Fig. 5 Contents refined from coaxial electrospraying for education in Junior Middle School about physics - forces.

\section{TEACHING MATERIALS FOR CHEMISTRY AND ASSOCIATION LEARNING}

In China, the students in the ninth grade in junior high school will open the new school subject for them - chemistry. In the beginning of chemical lessons, the contents are often chemical elements, molecules, atoms and chemical bonds (such as hydrogen bonds). With some real materials such as drug ferulic acid and polymer powders (polyvinylpyrrolidone,PVP) [22] as accompanied teaching materials (Fig. 6), an association learning of invisible chemical elements/molecules with applied materials, and science and technology should be a good format for the students.

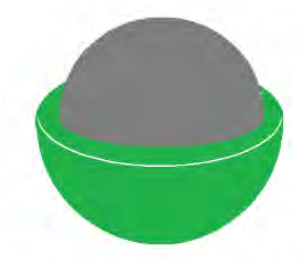

\section{Core-shell particle}

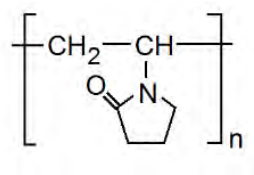

PVP

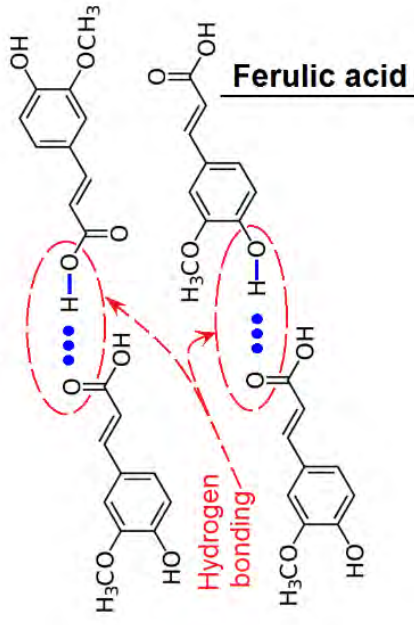

Fig. 6 Contents refined from advanced materials for education in Junior Middle School about chemistry - atom, molecule and the chemical bond [22]

\section{TEACHING MATERIALS FOR ANALOGICAL AND ASSOCIATION LEARNING}

For students in junior high school, it is time for the cultivation of their logical thinking ability, and also the application in achieving new knowledge. Analogical and also the related integrated learning should be parts of their routine studies in the school subjects. In this aspect, modern advanced techniques can provide many opportunities for the training of logical thinking and learning capability. Shown in Fig. 7 is a comparison of a series of spraying processes. Through analogical and integrated learning, it should be easier and deeper for the students to grasp the knowledges in a systematic manner through the comparisons of the working processes, the produced results, and also the fundamental mechanisms.

Fig. 7A is digital picture about the phenomena during an electrospraying process, in which a Taylor cone is formed by the electrical forces (Fig. 7A2) from a droplet (Fig. 7A1) [23-29]. In contrast, Fig. 7B to 7F are spraying of pesticides, perfume, water and oral spraying of medicine, respectively, these spraying is generated by the mechanical pressures. The differences with different kinds of forces (electrical forces and mechanical forces) determine their different results in generate final products. Both the processes, the products and also mechanisms can be imparted to the students in an analogical and integrated manner for a better learning effect.

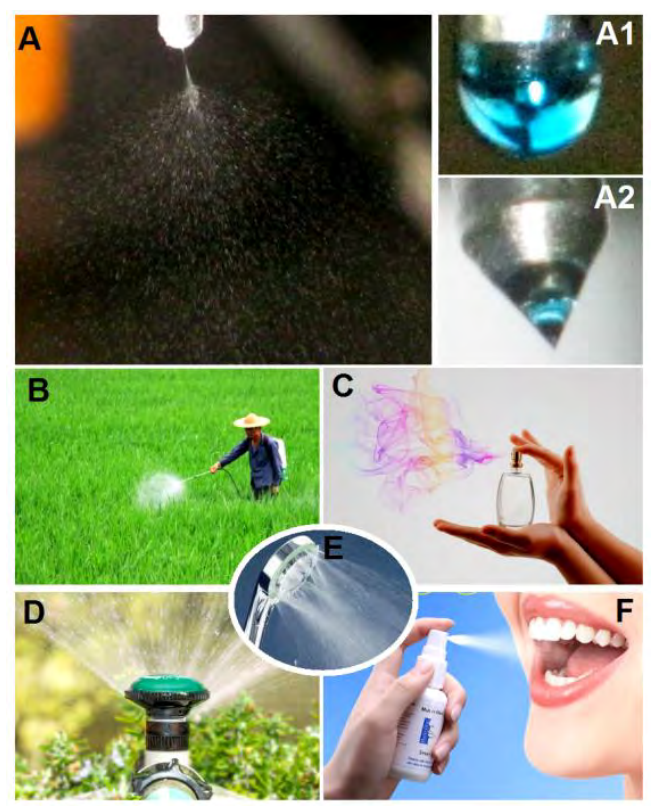

Fig. 7 Contents refined from advanced techniques for education in Junior Middle School about practices and analogical and integrated learning. A-electrospraying, A1 and A2 - droplets before and later of the applied high voltages [2]; B - spraying of pesticides; C-spraying of perfume; D and E-spraying of water; F- oral spraying of medicine.

\section{SUMMARY}

As an advanced learning method, association learning and also integrated learning should be gradually taught to the students in junior high school when they are studying the school subjects. The modern techniques, here electrospraying is exploited as an example, can act as a useful clue to link the studies of a series of school subjects such as "science", "mathematics", "physics", "chemistry" and "practice". The advanced techniques are the results of the developments of our modern science and technology. Inversely, they can provide numerous interesting teaching materials for the education at all levels, including junior high school. Some examples about the refined materials from electrospraying and electrosprayed 
products that can be utilized for the association learning of above-mentioned subjects, and also analogical and integrated learning methods are put forward. Certainly, these contents should be also fine materials for school-based training of the teachers in junior high school.

\section{ACKNOWLEDGMENT}

The financial supports are from the Shanghai Education Science Research Project (C17058) and the National Nature Science Foundation of China (51373101).

\section{REFERENCES}

[1] Z.P. Liu, Y.Y. Zhang, D.G. Yu, D. Wu, andH.L. Li, "Fabrication of sustained-release zein nanoparticles via modified coaxial electrospraying,” Chem. Eng. J., vol.334, pp.807-816, 2018.

[2] X.Y. Li, Z.B. Zheng, D.G. Yu, X.K. Liu, Y.L. Qu, andH.L. Li, "Electrosprayed sperical ethylcellulose nanoparticles for an improved sustained-release profile of anticancer drug," Cellulose, vol.24, pp.5551-5564, 2017.

[3] D.G. Yu, J.J. Li, G.R. Williams, and M. Zhao, "Electrospun amorphous solid dispersions of poorly water-soluble drugs: A review," J. Control. Release, vol. 292, pp.91-110, 2018.

[4] D.G. Yu, C. Yang, M. Jin, G.R. Williams, H. Zou, X. Wang, et al, "Medicated Janus fibers fabricated using a Teflon-coated side-by-side spinneret," Colloid. SurfaceB, vol.138, pp.110-116, Feburary 2016.

[5] Y.H. Wu, D.G. Yu, H.P. Li, X.Y. Wu, and X.Y. Li, "Medicated structural PVP/PEG composites fabricated using coaxial electrospinning," e-Polymers, vol.17, pp.39-44, January 2017.

[6] C. Yang, D.G. Yu, D. Pan, X.K. Liu, X. Wang, S.W.A. Bligh, et al, "Electrospun $\mathrm{pH}$-sensitive core-shell polymer nanocomposites fabricated using a tri-axial processes," Acta Biomater., vol.35, pp.77-86, April 2016.

[7] D.G. Yu, X. L. Zheng, Y. Yang, X. Y. Li, G.R. Williams, M. Zhao, "Immediate release of helicid from nanoparticles produced by modified coaxial electrospraying," Appl. Surf. Sci., 2019 (In publication).

[8] Y.Y. Yang, Z.P. Liu, D.G. Yu, K. Wang, P. Liu, X. Chen, "Colon-specific pulsatile drug release provided by electrospun shellac nanocoating on hydrophilic amorphous composites," Int. J. Nanomed., vol.2018, pp. 2395-2404, 2018.

[9] Q. Wang, D.G. Yu, L.L. Zhang, X.K. Liu, Y.C. Deng, and M. Zhao, "Electrospun hypromellose-based hydrophilic composites for rapid dissolution of poorly water-soluble drug," Carbohydr. Polym., vol.174, pp.617-625, Oct, 2017.

[10] Y. Yang,W. Li,D.G. Yu,G. Wang,G.R. Williams, Z. Zhang, "Tunable drug release from nanofibers coated withblankcellulose acetate layers fabricated usingtri-axial electrospinning," Carbohydr. Polym., vol.203, pp.228-237, 2019.

[11] K. Wang, X.K. Liu, X.H. Chen, D.G. Yu, Y.Y. Yang, and P. Liu, "Electrospun hydrophilic Janus nanocomposites for the rapid onset of therapeutic action of helicid,"ACS Appl. Mater. Interfaces, vol.10, pp.2859-2867, 2018.

[12] PDavoodi, LYLee, QXu, VSunil, YSun,SSoh, and C.-HWang, "Drug delivery systems for programmed and on-demand release," Adv. Drug Deliv. Rev., vol.132, pp. 104-138, 2018.

[13] Y. Xu, J.J. Li, D.G. Yu, G.R. Williams, J.H. Yang, and X. Wang, "Influence of the drug distribution in electrospun gliadin fibers on drug-release behavior," Eur. J. Pharm. Sci., vol.106, pp.422-430, August 2017.

[14] Z. Zhang, W. Li, G. Wang, Y.L. Qu, and D.G. Yu, "Electrospun 4th generation solid dispersions of poorly water-soluble drug utilizing two different processes," J. Nanomater. Vol.2018, Article ID 2012140, 2018.

[15] Q. Wang, D.G. Yu, S.Y. Zhou, C. Li, and M. Zhao, "Fabrication of amorphous electrospun medicated-nanocomposites using a Teflon-based concentric spinneret," e-Polymer, vol.18, pp.3-11, 2018.
[16] H.F. Wen, C. Yang, D.G. Yu, X.Y. Li, D.F. Zhang, "Electrospun zein nanoribbons for treatment of lead-contained wastewater," Chem. Eng. J., vol.290, pp.263-272, 2016 .

[17] D.G. Yu, J.J. Li, M. Zhang, and G.R. Williams, "High-quality Janus nanofibers prepared using three-fluid electrospinning," Chem. Commun., vol.53, pp.4542-4545,April 2017.

[18] Y.Y. Yang, M. Zhang,K. Wang, and D.G. Yu, "pH-sensitive polymer nanocoating on hydrophilic composites fabricated using modified coaxial electrospraying," Mater. Lett., vol.227, pp. 93-96, 2018.

[19] M. Jin, D.G. Yu, X. Wang, C.F.G.C. Geraldes, G.R. Williams, and S.W.A. Bligh, "Electrospun contrast agent-loaded fibers for colon-targeted MRI," Adv. Healthcare Mater., vol.5, pp.977-985, April 2016.

[20] T. Hai, X. Wan, D.G. Yu, K. Wang, Y. Yang, Z.P. Liu, "Electrospun lipid-coated medicated nanocomposites for an improved drug sustained-release profile," Mater. Design, vol.162, pp.70-79, 2019.

[21] Y.Y. Yang, M. Zhang, Z.P. Liu, K. Wang, andD.G. Yu, "Meletin sustained-releasegliadin nanoparticles prepared via solvent surface modification on blending electrospraying,"App. Surf. Sci., vol.434, pp.1040-1047, 2018.

[22] W. Huang, Y. Yang, B. Zhao, G. Liang, S. Liu, X.-L. Liu, and D.G. Yu, "Fast dissolving of ferulic acid via electrospun ternary amorphous composites produced by a coaxial process," Pharmaceutics, vol.10, Article ID115 (12 pages), 2018

[23] X. Liu, W. Shao, M. Luo,J. Bian,D.G. Yu, "Electrospun blank nanocoating for improved sustained release profiles from medicated gliadin nanofibers,"Nanomaterials, vol.8, Article ID 184 (11 pages), 2018.

[24] K. Wang, H.F. Wen, D.G. Yu, Y. Yang, and D.F. Zhang, "Electrosprayed hydrophilic nanocomposites coated with shellac for colon-specific delayed drug delivery," Mater. Design, vol.143, pp.248-255, 2018.

[25] Z.P. Liu, L.L. Zhang, Y.Y. Yang, D. Wu,G. Jiang, andD.G. Yu, "Preparingcomposite nanoparticles for immediate drug release by modifying electrohydrodynamic interfaces during electrospraying," Powder Technol., vol.327, pp.179-187, 2018.

[26] X. Liu, Y. Yang, D.G. Yu, M.J. Zhu, M. Zhao, G.R. Williams, "Tunable zero-order drug delivery systems created by modified triaxial electrospinning," Chem. Eng. J., vol. 356, pp.886-694, 2019.

[27] J.J. Li, Y.Y. Yang, D.G. Yu, Q. Du, X.L. Yang, "Fast dissolving drug delivery membrane based on the ultra-thin shell of electrospun core-shell nanofibers,"'Eur. J. Pharm. Sci., vol.107, pp. 195-204, 2018.

[28] Y. Yang,W. Li,D.G. Yu,G. Wang,G.R. Williams, Z. Zhang, "Tunable drug release from nanofibers coated withblankcellulose acetate layers fabricated usingtri-axial electrospinning," Carbohydr. Polym., vol.203, pp.228-237, 2019.

[29] M. Jin, D.G. Yu, C.F.G.C. Geraldes, G.R. Williams, and S.W.A. Bligh, "Theranostic fibers for simultaneous imaging and drug delivery," Mol. Pharm., vol.13, pp.2457-2465, July 2016. 